\title{
Comparison of accelerator based radioisotope production potentials in medical imaging
}

\author{
Şeyda AKÇAY ${ }^{1}$ (D) Sinan KUDAY ${ }^{2 *}$ (D) \\ ${ }^{1}$ Istanbul Aydin University, Health Science Institute, Medical Physics, 34295, Istanbul / Turkey \\ ${ }^{2}$ Istanbul Aydın University, Application and Research Center For Advanced Studies, 34295, Istanbul / Turkey
}

\begin{abstract}
Most recent production capabilities of highly demanded radiosotopes in medical diagnosis and imaging is not as high as the increasing number of patients worldwide. We studied radioisotope production efficiencies of ${ }^{99 \mathrm{~m}} \mathrm{Tc},{ }^{111} \mathrm{In},{ }^{18} \mathrm{~F},{ }^{11} \mathrm{C},{ }^{125,124} \mathrm{I},{ }^{67} \mathrm{Ga},{ }^{64} \mathrm{Cu}$ ve ${ }^{86} \mathrm{Y}$ at medical accelerators through hadronic collision simulations by Geant 4 . We considered to recent production parameters and calculated the optimal values for parameters such as Qvalue, cross section, production energy and irradiation yields. This study also aimed to shed light on the radionuclide production in the region.
\end{abstract}

Article info
History:

Received:18.09.2019

Accepted:13.12.2019

Keywords:

Geant4, ROOT,

Radioisotope,

Simulation.

\section{Introduction}

Radiopharmaceuticals are active molecules used in the diagnosis and treatment of nuclear medicine. Radiopharmaceutical consists of two parts: radionuclide and pharmaceutical part [1]. Radiopharmaceuticals also show involvement in certain organs according to the physical, chemical and biological properties of the pharmaceutical part. Then the organ functions can be imagined or treated with the radiation emitted by the transported radionuclide. Anatomical informations are obtained by imaging the distribution of radionuclide in the organism, while physiological informations are obtained by determining the changes of this distribution over time. Gamma-emitting radionuclides are used for diagnostic purposes, and beta-emitting radionuclides are used for therapeutic purposes. In nuclear medicine, radionuclides are produced entirely, is based on the detection and reconstruction of gamma photons that decayed by the radiotracers introduced into the body before the process. A SPECT system contains gamma cameras that is fixed on the gantry and rotates around the target (body) that is of interest recording the twodimensional projection of a three-dimensional activity distribution of radiotracers [2]. Afterwards, a serial algorithms are executed to reconstruct the three dimensional real-like images from acquired twodimensional images by the SPECT system. As a medical imaging technique, SPECT, can be considered together with a CT system that forms the hybrid usage of both technologies named as SPECT / CT. Considering their scan geometries, 5 generations of CT systems may be classified for multi purposes by the time they are firstly introduced in 1960s [3, 4]. Fifth generation CT systems are convenient to make the detection by synthetic ways and more than 2700 radionuclides are produced by cyclotron, reactor and generators. In nuclear medicine, it is aimed that the patient is diagnosed by applying the lowest possible dose of radiopharmaceuticals [3]. Dose response relationship is not observed as trace amounts of pharmaceuticals do not cause pharmacological effect like other drugs during the preparation of radiopharmaceuticals.

In this study, accelerator-based production and potentials of ${ }^{99 \mathrm{~m}} \mathrm{Tc},{ }^{111} \mathrm{In},{ }^{18} \mathrm{~F},{ }^{11} \mathrm{C},{ }^{125,124} \mathrm{I},{ }^{67} \mathrm{Ga},{ }^{64} \mathrm{Cu}$ ve ${ }^{86} \mathrm{Y}$ isotopes that frequently used in medical radiopharmaceuticals will be discussed. These productions will be researched in the simulation environment and the multiplicity of the related reactions and optimum production parameters will be presented. The development in nuclear medicine have 
increased the need for radionuclide production. This study also aimed to set light on radionuclide production of the country. Criteria such as purity, efficiency and safety in the production of radionuclides can be determined with high precision by realistic simulations.

\section{Materials and Methods}

The radioisotopes that is in the production of interest list as ${ }^{99 \mathrm{~m}} \mathrm{Tc},{ }^{111} \mathrm{In},{ }^{18} \mathrm{~F},{ }^{11} \mathrm{C},{ }^{125,124} \mathrm{I},{ }^{67} \mathrm{Ga},{ }^{64} \mathrm{Cu}$ ve ${ }^{86} \mathrm{Y}$ have been chosen by their clinical usage frequencies and average production energies. One can see a detailed comparison of materials with respect to their half-life, decay types, gamma energy irradiations, absorbed organs/tissues and clinical usage in Table 1. It is a known fact that, clinically, the most preferred radioisotopes in SPECT or PET imaging are ${ }^{99 \mathrm{~m}} \mathrm{Tc}$, ${ }^{18} \mathrm{~F}$ and ${ }^{11} \mathrm{C}$ if one made a consideration with organs that they have effected and half-lifes. However, an oncologist can decide to use any of these for extreme cases or clinical purposes.

One can calculate Q-values and cross section parameters by applying basic physics principles for a nuclear reaction of type $\mathrm{a}+\mathrm{X}>\mathrm{Y}+\mathrm{b}$ as follows;

$Q=\left\{m_{\text {initial }}-m_{\text {final }}\right\} c^{2}=E_{Y}+E_{b}-E_{X}-E_{a}$ where $E$ denotes the each kinetic energies for the indexed particles. However, a more accurate value can be calculated if one considers scattering directions and decaying products carefully. One can calculate the neutron scattering cross section for the above mentioned nucler reaction as follows;

$\sigma_{\text {scat }}=\frac{N_{\text {scat }}}{N_{\text {total }}} \frac{M T}{N_{A} \rho}$

where $N_{\text {scat }}$ denotes the number of scattered neutrons, $N_{\text {total }}$ is the number of incident neutrons, $M$ is the molar mass of target, $T$ thickness of target, $\rho$ is the density of target and $\mathrm{N}_{\mathrm{A}}$ is Avogadro's number. The yield of a nuclear reaction is used for a good indicator of how often a nuclear reaction occurs in the set of a specific parameters as follows;

$Y(E)=\frac{N_{A} I}{A}\left(1-e^{(-\lambda t)}\right) \int_{E 0}^{E} \sigma(E) \frac{d E}{S_{T}(E)}$

where $I$ is the incident particle flux per second that is related to the beam current, $\mathrm{A}$ is the atomic weight in ( $\mathrm{g} / \mathrm{mol}), \lambda$ is decay constant that equals to $0.693 /$ halflife, $S_{T}(E)$ denotes the stopping power with respect to energy, $d E$ is differential loss in the energy and $t$ denotes irradiation time.

We have tabulated and justified our calculations with the Geant 4 results as in the Table 2 of the Section-IV. 
Table 1. A detailed explanations of radioisotope key feauteres used in medical radiopharmaceuticals

\begin{tabular}{|c|c|c|c|c|c|}
\hline Radioisotope & Half-life & $\begin{array}{l}\text { Decay } \\
\text { Type } \\
(\%)\end{array}$ & $\begin{array}{l}\text { Gama } \\
\text { Energy } \\
(\mathrm{keV})\end{array}$ & Absorbed organ or tissue & Clinical Usage \\
\hline${ }^{99 \mathrm{~m}} \mathrm{Tc}$ & $6.05 \mathrm{~h}$ & IT(100) & 140 & $\begin{array}{l}\text { Myocardial,brain, kidney, } \\
\text { neuroendocrine tumors, ventricles, } \\
\text { lung tumors [5], bone, tumor, lung, } \\
\text { liver, splenic, bone marrow, capillary } \\
\text { bed of the lung, kupffer cells, [4] }\end{array}$ & $\begin{array}{c}\text { Scintigraphy, direct/indirect } \\
\text { radionuclide cystography, SPECT } \\
\text { imaging, myocardial perfusion imaging } \\
\text { [4] renal function, Gastrointestinal } \\
\text { bleed-spleen imaging, Regional } \\
\text { cerebral perfusion, Hepatobiliary } \\
\text { system [8] }\end{array}$ \\
\hline${ }^{111} \mathrm{In}$ & $2.8 \mathrm{~d}$ & $\mathrm{EC}(100)$ & $171 ; 245$ & $\begin{array}{l}\text { Neuroendocrine tumors [5], liver, } \\
\text { splenic, bone marrow [7] }\end{array}$ & $\begin{array}{c}\text { Radionuclide cisternography, marked } \\
\text { leukocyte scintigraphy, somatostatin } \\
\text { receptor scintigrapy, [4], } \\
\text { musculoskeletal infection and } \\
\text { inflammation, pulmonary infection, } \\
\text { abdominal infection [7] }\end{array}$ \\
\hline${ }^{18} \mathrm{~F}$ & $109.8 \mathrm{~min}$ & $\beta+(97)$ & 511 & $\begin{array}{l}\text { Tumors,brain,myocardial,hypoxia in } \\
\text { tumor,endometrial cancer [5] heart, } \\
\text { urinary systems [4], macrophages } \\
\text { [11], bone [12] }\end{array}$ & $\begin{array}{l}\text { PET/CT [4], PET/MRI [9] , FDG-PET } \\
\text { imaging, bone tumors, [10] }\end{array}$ \\
\hline${ }^{11} \mathrm{C}$ & $20.4 \mathrm{~min}$ & $\beta+(100)$ & 511 & $\begin{array}{l}\text { Tumors, neuroinflamattion [5] heart } \\
\qquad[11]\end{array}$ & $\mathrm{PET} / \mathrm{CT}[4]$ \\
\hline${ }^{124} \mathrm{I}$ & $4.2 \mathrm{~d}$ & $\begin{array}{l}\beta+(23), \\
\mathrm{EC}(77)\end{array}$ & 511 & Lung tumors [4], lung & $\begin{array}{l}\text { PET imaging, thyroid disease [5], } \\
\text { Infection Imaging }\end{array}$ \\
\hline${ }^{123} \mathrm{I}$ & $13.22 \mathrm{~h}$ & $\mathrm{EC}(100)$ & 159 & Brain, muscle, thyroid, kidney & $\begin{array}{l}\text { Myocardial Imaging, Monitoring of } \\
\text { blood flow in brain, diagnosis of } \\
\text { neurological diseases (Ex: Alzheimer) }\end{array}$ \\
\hline${ }^{67} \mathrm{Ga}$ & $3.3 \mathrm{~d}$ & $\mathrm{EC}(100)$ & $\begin{array}{c}93 ; 184 \\
300\end{array}$ & $\begin{array}{l}\text { Neoplastic region, inflammatory } \\
\text { region, tumor cells, lymphoma tumor, } \\
\text { soft tissue, head-neck, lung tumors, } \\
\text { melanoma, neuroblastoma [4], liver, } \\
\text { bone marrow, splenic, kidney [7] }\end{array}$ & $\begin{array}{c}{ }^{67} \text { Ga scintigrapy [4], infection and } \\
\text { inflammation imaging [7] }\end{array}$ \\
\hline${ }^{64} \mathrm{Cu}$ & $12.8 \mathrm{~h}$ & $\begin{array}{c}\beta+\text { veya } \\
\beta-, \text { EC }\end{array}$ & 511 & Hypoxia in tumor & PET/CT, MRI [10], Infection Imaging \\
\hline${ }^{86} \mathrm{Y}$ & $14.7 \mathrm{~h}$ & $\beta+(33)$ & 660 & Liver, Kidneys and spleen & $\mathrm{PET} / \mathrm{CT}[4]$, \\
\hline
\end{tabular}




\section{III.Geant4 Simulations}

\subsection{Simulation setup:}

We aimed to simulate corresponding nuclear processes via installing a simple setup focusing on the beam parameters such as beam current and luminosity rather than accelerator parameters. We considered the targets in a box with each dimension is $10 \mathrm{~m}$ and performed fixed target hadronic collisions where the beam consisting of protons with $10 \mathrm{MeV}$ energy. Initially, we kept box sizes as large as possible to measure event production ratios.

\subsection{Simulation specifications:}

Hadronic physics processes are included and selected as the nature of the each nuclear reactions. They include : HadronElastic (including neutronHP), HadronInelastic, IonsInelastic, GammaNuclear physics, RadioactiveDecay and electromagnetic. The simulated data acquired by each process generated with 100000 events with a ion particle gun. Geant4 computes and plots energy deposited in the interaction volume (absorber) and the flux of particles leaving the box volume. Geant 4 code prepared as the extended hadronic examples of the framework. Energy spectrum of scattered alphas, gammas, neutrons and kinetic energy of nucleus for each process are recorded as ROOT [13] outputs. We present the analysis of these outputs in Section IV.

Table 2. Q Values, Cross sections, production energy and event number in 100000 proton collision events for each process

\begin{tabular}{|c|c|c|c|c|}
\hline Production Process & Q Values (MeV) & Cross Section $(\mathrm{mb})$ & Mean Energy (MeV) & Production Event Number \\
\hline N-14(p,alpha)C-11 & -2.922 & 0.037 & 6.1327 & 60 \\
\hline Ni-64(p,n)Cu-64 & -2.460 & 4.34 & 0.4878 & 1448 \\
\hline O-18(p,n)F-18 & -2.439 & 0.728 & 1.546 & 19850 \\
\hline Zn-68(p,2n)Ga-67 & -11.986 & 24.377 & 0.526 & 25192 \\
\hline Te-124(p,2n)I-123 & -11.444 & 40.476 & 0.289 & 3037 \\
\hline Te-124(p,n)I-124 & -3.951 & 4.8795 & 0.246 & 21018 \\
\hline Cd-112(p,2n)In-111 & -11.046 & 31.79 & 0.323 & 5105 \\
\hline Mo-100(p,2n)Tc-99m & -7.865 & 7.221 & 0.356 & 262 \\
\hline Sr-86(p,n)Y-86 & -6.028 & 0.3602 & 0.365 & \\
\hline
\end{tabular}

\section{Comparison and Analysis Of Productions}

Comparison of results are obtained by the stack plots in arbitrary units as shown in Fig.1-4 for kinetic energy distributions of produced nuclei, scattered alpha, gamma and neutron particle distributions, respectively. We have accelerated 100000 protons with $10 \mathrm{MeV}$ kinetic energy to hit on a fixed target for each production processes. From collected data, we analytically calculated the yield values as in equation [3] and ordered in the legend key with respect to the yields as in Fig. 5, respectively. 124I and 86Y are concluded considerably at low values to be produced at accelerators for considered process and parameters. The main reason is naturally half - life of related radioisotopes as shown in Table 1 . We obtained promising yield values for 123I , 18F and 99Tc and this result proves the reason why they are mostly preferred by clicinical purposes. 


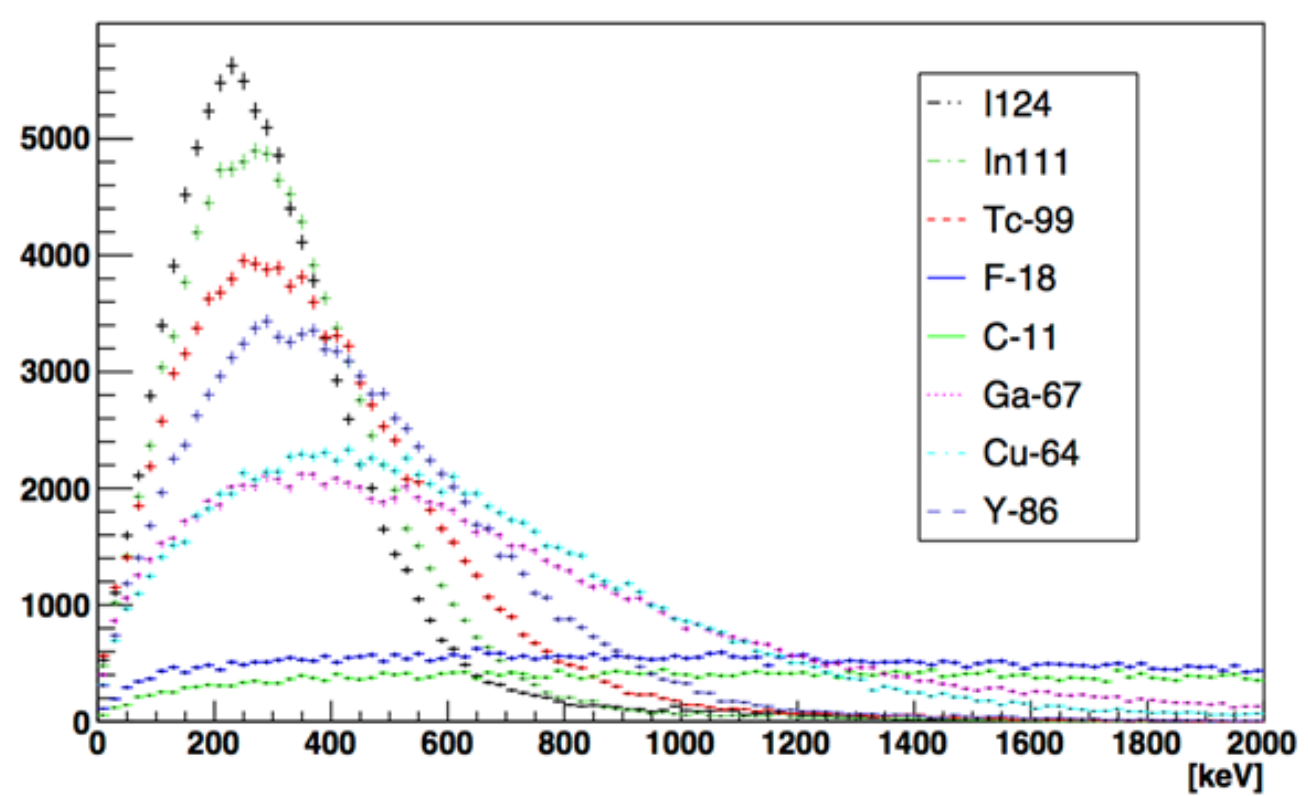

Figure 1. Kinetic energy distributions of produced nuclei for each considered radioisotope

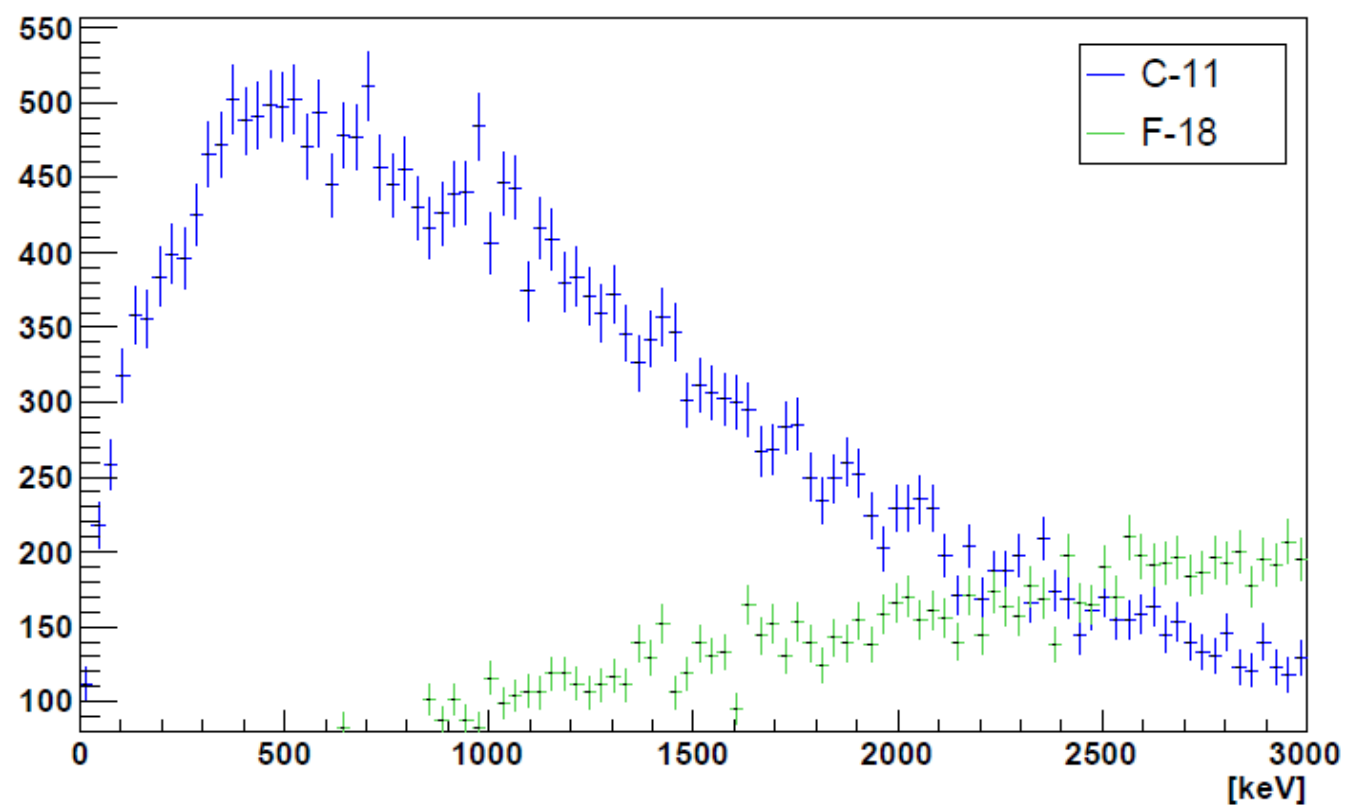

Figure 2. Energy distributions of scattered alpha particles for N-14(p,alpha)C-11 [green] and O-18(p,n)F-18 [blue]. No other significant alpha distributions are observed for considered radioisotope productions 


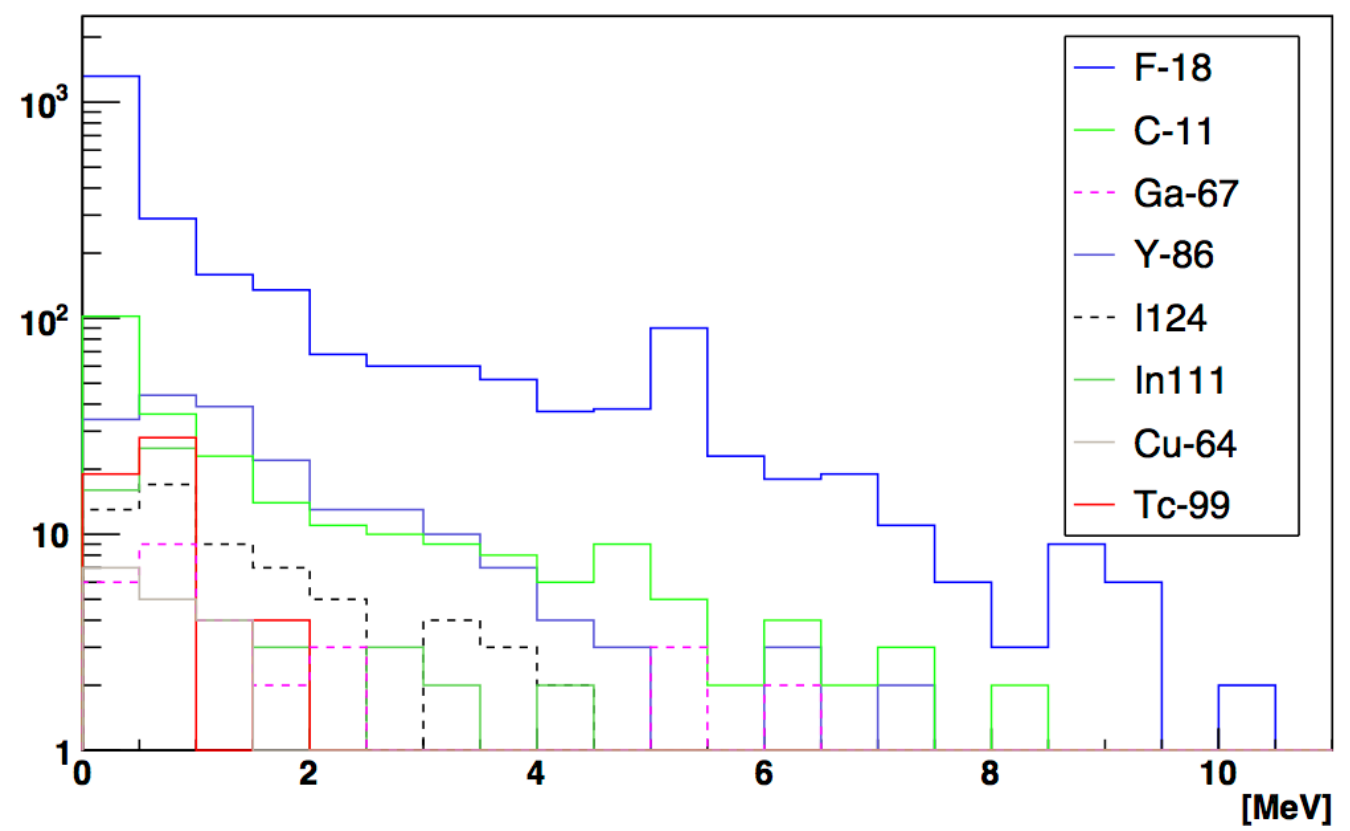

Figure 3. Energy distributions of scattered gamma particles for each considered radioisotope productions

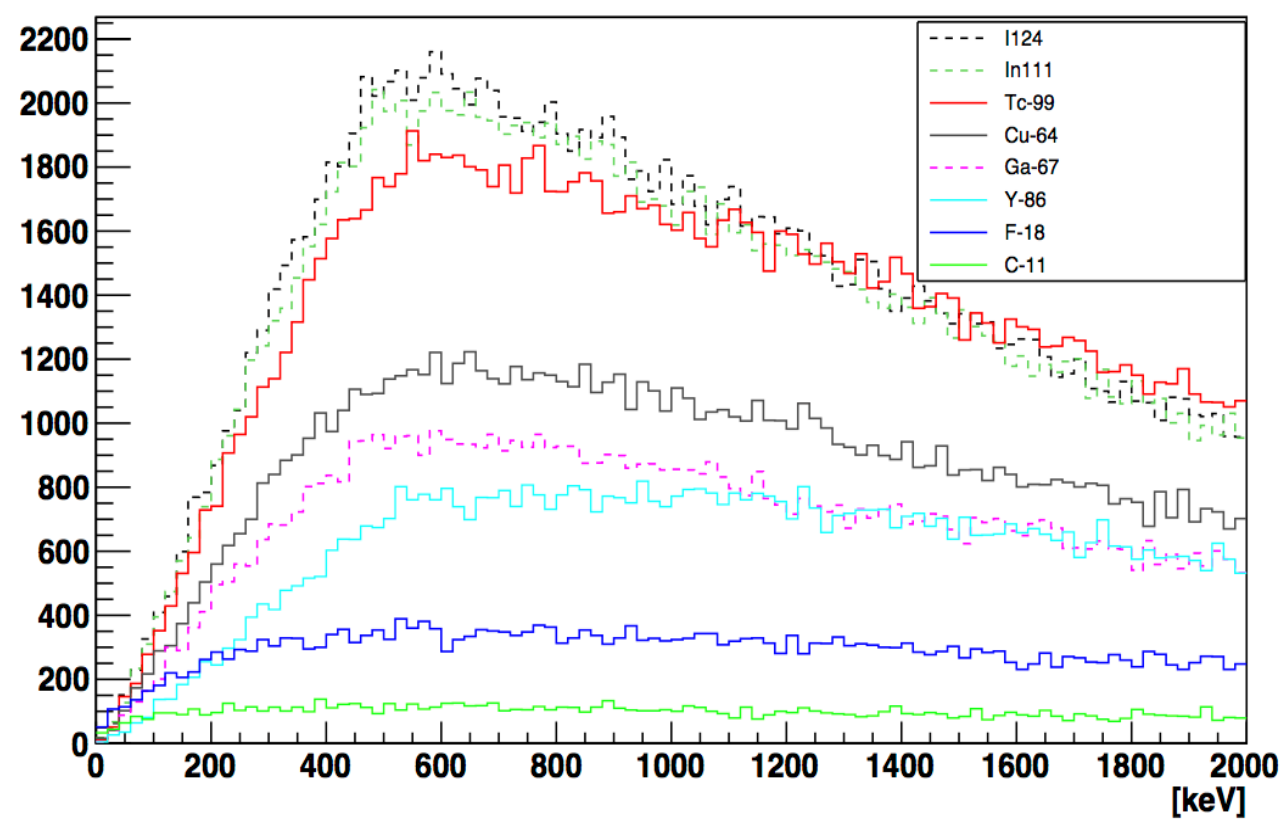

Figure 4. Energy distributions of scattered neutron particles for each considered radioisotope productions. 


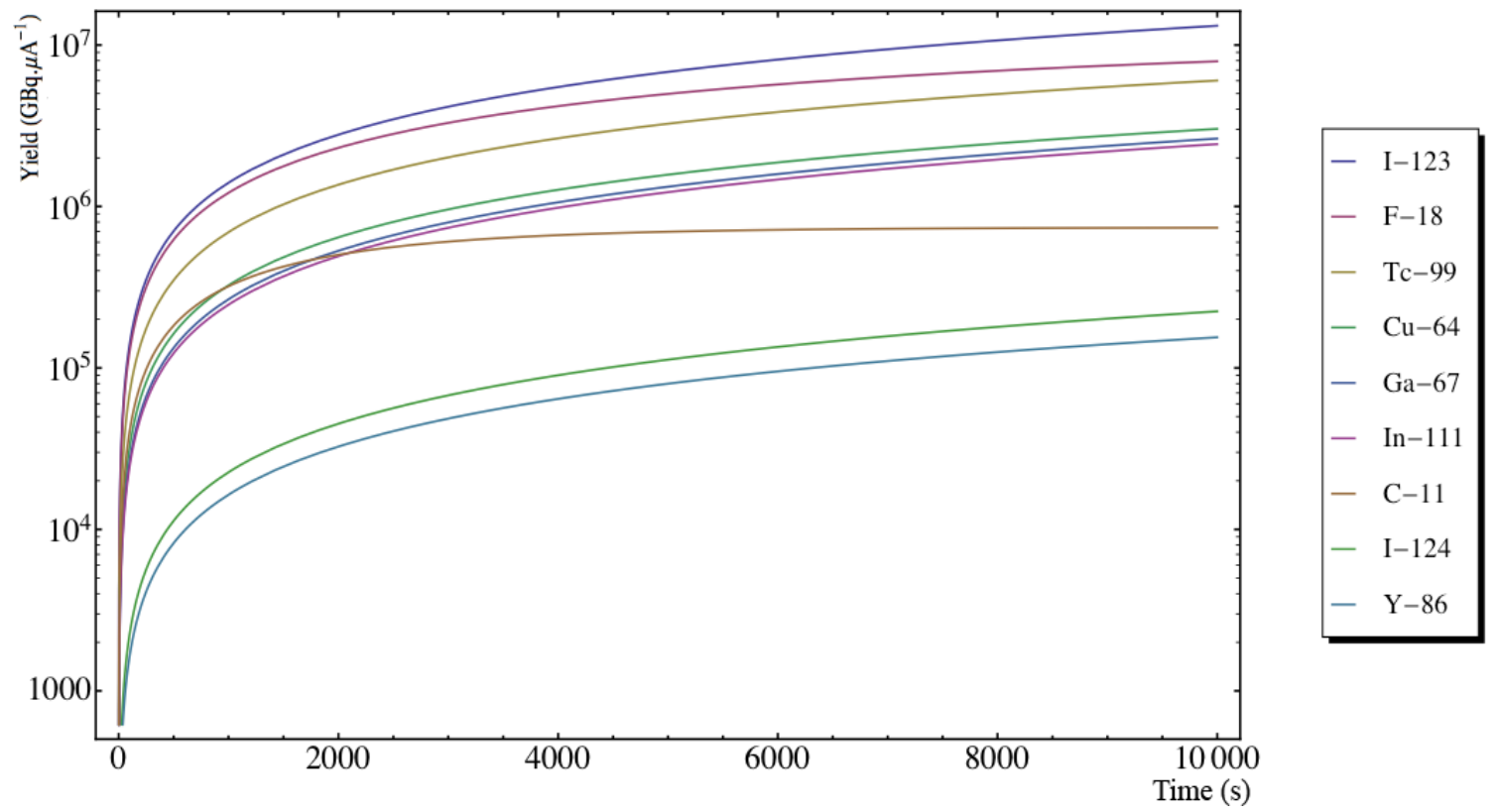

Figure 5. Comparison of radioisotope yields versus irradition time of beam after analysis for each produced radioisotope.

\section{Conclusion}

In this paper, we have virtually simulated an optimistic approach for radioisotope production and presented the analysis results as in the related figures and tables. If accelerator and collider facilities are getting more compact and cheaper in the near future as predicted, radioisotope productions that are needed in medical imaging and diagnosis can be provided by modern methods more efficiently and faster.

In this case, with 7, 5, $3 \times 10^{6} \mathrm{GBq} \cdot \mu \mathrm{A}^{-1}$ yield values respectively; ${ }^{123} \mathrm{I},{ }^{18} \mathrm{~F}$ and ${ }^{99} \mathrm{Tc}$ seem to be produced in high quantities to prepare a radiopharmaceutical if the beam irradiation time is more than 2.23 hours. Moreover, ${ }^{86} \mathrm{Y}$ and ${ }^{124} \mathrm{I}$ are predicted to be produced in the least quantities comparing with other considered radioisotopes as in order of 100 yield values.

\section{References}

[1] Smith N.B., Webb A., Nuclear medicine: planar scintigraphy, SPECT and PET/CT. Introduction to Medical Imaging: Physics, Engineering and Clinical Applications. 1st ed. Cambridge University Press the Edinburgh Building; (2011), 89-139.

[2] Gündoğdu E., Özgenç E., Ekinci M., İlem Özdemir D., Aşıkoğlu M., Radiopharmaceuticals Used in Imaging and Treatment in Nuclear Medicine, Journal of Literature Pharmacy Sciences, 7(1) (2018) 24-34.
[3] Patient Care, What is Nuclear Medicine, What is PET/CT ? What are the benefits of Nuclear Medicine Adress: http://med.stanford.edu/nuclearmedicine/patient_ care.html Retrieved Sept. 182019.

[4] Demir M., Nükleer Tıp Fiziği ve Klinik Uygulamaları, İstanbul Üniversitesi Tıp Fakültesi Yayınlar1, 4. Bask1, (2014).

[5] Teksöz S., Müftüler F.Z.B., Radioisotopes and Biomedical Applications in Nuclear Medicine, Nucl Med Seminerleri 5 (2019) 10-14.

[6] What is a radiopharmaceutical? Adress: https://www.insideradiology.com.au/nuclearmedicine/ Retrieved Sept. 18 (2019).

[7] Ertay T.,Infection-Inflammation: SPECT Radiopharmaceuticals for Molecular Imaging/Enfeksiyon-Enflamasyon: Molekuler Goruntulemede Kullanilan SPECT Radyofarmasotikleri., Nuclear Medicine Seminars, 2(2) (2016) 63+. Gale Academic OneFile, Accessed Sept. 182020.

[8] Frederic H. Fahey et. al., Nuclear Medicine and Radiation Protection, Journal of Radiology Nursing, 35(1) (2016).

[9] Akdemir Ü.Ö., Karabacak N.İ., Atay L.Ö., Positron Emission Tomography/Magnetic Resonanse Imaging Applications in Neurologic Imaging, Nuclear Medicine Seminars 1 (2017) 52-58. 
[10] About Imaging Agents Or Tracers, Adress: https://www.acrin.org/PATIENTS/ABOUTIMA GINGEXAMSANDAGENTS/ABOUTIMAGIN GAGENTSORTRACERS.aspx Retrieved Sept. 182019.

[11] E. Özdemir, D. Bedel, Advances in Nuclear Cardiology: Instrumentation, Software and Radiopharmaceuticals, Nucl. Med. Semin. 4 (2018) 145-156.
[12] Ocak M., Radiopharmaceuticals for PET, Toraks Cerrahisi Bülteni 6 (2015) 154-160.

[13] R. Brun and F. Rademakers, ROOT - An Object Oriented Data Analysis Framework, Proceedings AIHENP'96 Workshop, Lausanne, Sep. 1996, Nucl. Inst. \& Meth. in Phys. Res. A 389 (1997) 8188. 